\title{
A MASSIFICAÇÃO DOS CONTRATOS À LUZ DO DIREITO DO CONSUMIDOR
}

Roberto Alves de Oliveira Filho

ISSUE DOI: $10.21207 / 1983.4225 .257$

\section{RESUMO}

O presente trabalho versa sobre a crescente demanda do Direito Contratual relacionado ao Direito do Consumidor, no que tange aos contratos de adesão, como instrumento de contratação em massa e apresentando a revisão contratual como uma possível medida para a redução da desigualdade negocial entre consumidor e fornecedor.

Palavras-chave: Direito Civil. Direito do Contratual. Direito do Consumidor.

\section{INTRODUÇÃO}

É indubitável que a Constituição Federal de 1988 foi responsável pela recodificação do direito privado no Brasil, na medida em que a inseriu na rota das normas de direito privado o objetivo de dar efetividade às suas diretrizes.

Em que pesem as discussões doutrinárias, o mais importante a ser frisado é que o Código Civil de 2002, ao recepcionar da Constituição princípios tais como da dignidade da pessoa humana e da solidariedade, 
contribuiu para a consolidação dos princípios infraconstitucionais da eticidade, da socialidade e da operabilidade, resgatando a importância da ética nas relações privadas, algo que havia sido relegado a um plano secundário na antiga codificação.

Hodiernamente, o redirecionamento dado ao direito privado pela Constituição a transforma em um ponto central do novo Direito Civil brasileiro, com viés social e voltado à proteção dos vulneráveis. Conforme aduz a professora Cláudia Lima Marques, a Constituição seria a garantia e o limite de um direito privado construído sob seus valores (principalmente os direitos fundamentais), transformando-o em um direito privado solidário. ${ }^{1}$

O consumo é uma atividade inerente ao ser humano em meio social, uma vez que se torna indispensável para sua própria mantença. Por essa razão, durante toda a história da vida em sociedade, aqueles que têm o poderio no fornecimento de bens que promovam o desenvolvimento do homem, em todos os seus aspectos, estabelecem o assenhoramento, muitas vezes, relativizando alguns dos direitos mais básicos do consumidor, tais como o direito ao atendimento digno, que decorre de princípios constitucionais, mais precisamente do princípio da dignidade da pessoa humana.

Nessa senda, obtempera José Francisco Cunha Ferraz Filho que a relação de consumo é marcada pela desigualdade, sendo o consumidor considerado como hipossuficiente, ou seja, como alguém que dispõe de poucos meios ou mesmo nenhum meio de defesa contra as imposições do fornecedor, o que ensejou a criação de uma norma que regulamentasse tais situações. $^{2}$

Com efeito, é possível vislumbrar que o Código de Proteção e Defesa do Consumidor foi desenvolvido como um microssistema legislativo, na medida em que regula apenas as relações de consumo dentro dos macrossistemas, quais sejam os Códigos Civil e Comercial.

Trata-se, portanto, de um instituto legislativo moderno, pois somente as relações de consumo são regidas por ele, estando revogadas as normas do Código Civil, Código Comercial, Código de Processo Civil,

\footnotetext{
${ }^{1}$ MARQUES, Cláudia Lima. Manual de direito do consumidor. São Paulo: Revista dos Tribunais, 2008. p. 27.

${ }^{2}$ FERRAZ FILHO, José Francisco Cunha. In: COSTA MACHADO, Antônio Cláudio da. (Org.); CUNHA FERRAZ, Anna Cândida da. (Coord.). Constituição Federal interpretada. 3. ed. Barueri: Manole, 2012. p. 27.
} 
Código Penal, Código de Processo Penal e demais leis extravagantes, prevalecendo sempre a norma específica, in casu, a consumerista.

O legislador, consoante verifica no conteúdo dos dispositivos principiológicos da Constituição Federal, não regulamentou de forma direta os direitos e interesses do consumidor, apenas delineando os princípios que deveriam nortear a legislação de consumo, valendo-se, portanto, de normas programáticas com o escopo de proteger a figura do consumidor.

Nesse sentido é oportuna a lição trazida por Sônia Mello:

A inserção da defesa do consumidor, como princípio a ser observado nas atividades econômicas, torna obrigatória o respeito aos direitos do consumidor por parte do fornecedor, assim como do próprio Estado na elaboração de normas, na regulamentação e na fiscalização exercida por este, nas atividades produtivas do país. ${ }^{3}$

Como se nota, é evidente o diálogo das fontes entre o Código de Defesa do Consumidor e a Constituição Federal, haja vista que a vulnerabilidade, bem como associalidade, fundam-se na Magna Carta, que dispõe em seu prólogo, que o Estado Democrático de Direito colima realizar os valores fundamentais da dignidade da pessoa humana, do trabalho, da livre iniciativa, da solidariedade e da função social da propriedade, com o escopo de construir uma sociedade livre, justa e solidária, garantindo o desenvolvimento social e a erradicação da pobreza ( $\operatorname{arts.} 1^{\circ}$ e $3^{\circ}$ ).

No art. 170, V, tais valores são reafirmados ao tratar a figura do consumidor como força motriz da atividade econômica, incorporando assim, a influência do direito público sobre o direito privado, fenômeno chamado pela doutrina de constitucionalização do Direito Civil ou Direito Civil Constitucional.

Infere-se, portanto, que o macroprincípio constitucional da dignidade da pessoa humana compreende a isonomia que possibilita que os objetivos sociais sejam alcançados, reconhecendo-se a vulnerabilidade existente no mercado de consumo, cabendo ao Estado Democrático de

\footnotetext{
${ }^{3}$ MELLO. Sônia Maria Vieira de. O direito do consumidor na era da globalização: a descoberta da cidadania. - Rio de Janeiro: Renovar, 1998. p. 16.
} 
Direito assegurar a defesa do consumidor tendo por primazia a sua dignidade, o equilíbrio e a boa-fé nas tratativas civis-comerciais.

\section{CONCEITO DE CONSUMIDOR}

O termo consumidor possui várias acepções, sendo não apenas jurídica, mas econômica e política. Devido a seu vasto campo conceitual, a delimitação do consumidor como sujeito de direito originou inúmeras teorias e estudos no Brasil, na Espanha e em todo o mundo, sendo de grande valor a tarefa dos juristas e filósofos do direito na busca do estabelecimento de limites ao conceito de consumidor.

De acordo com os dicionários Aurélio e Houaiss de língua portuguesa, consumidor é pessoa que compra para uso próprio gêneros ou mercadorias. Para os economistas, o consumidor é um sujeito de mercado que adquire bens ou utiliza serviços com a finalidade de destiná-los à satisfação de suas necessidades pessoais ou familiares.

Malgrado estejam corretos esses conceitos, há uma preocupação maior dos juristas ao conceituar a figura do consumidor, pois ele é visto como o principal agente da vida econômica, pois para ele é voltado o esforço da produção, sendo a ele que se vendem produtos e serviços e que se busca seduzir com publicidade. Enfim, é o consumidor quem paga a conta da produção e é dele que vem o lucro do produtor.

Sua influência pode ser vislumbrada nos dois extremos da estrutura econômica, seja no ponto final da cadeia de produção, na qual ele adquire, consome e utiliza os produtos e serviços oferecidos e em outra etapa julgando-os e até mesmo selecionando-os.

Cumpre salientar que na outra ponta, a da produção, o consumidor ainda pode fazer-se ouvir, tanto pela sua reação negativa a um determinado produto, quanto pela manifestação de uma necessidade de consumo específica.

É mister que seja levado em consideração a existência de vários tipos de consumidores, sendo estes ricos e pobres, informados e desinformados, crianças, adultos e idosos, consumidores indefesos e capazes de se defenderem. Nesse sentido, Guido Alpa propugna pela defesa individualizada do consumidor, que atenda as suas particularidades e interes- 
ses específicos, e não como uma determinada classe existente na sociedade. $^{4}$

Para o Direito, o referido termo abarca vários sentidos, teorias e entendimentos doutrinários e jurisprudenciais. Nessa senda, não há um conceito jurídico-científico claro e único de consumidor, ainda que inexista qualquer relação entre os conceitos oriundos das suas várias fontes, em todas elas subjaz o mesmo tipo de adquirente ou usuário de bens e serviços que se tem a finalidade de proteger.

Aduz Antônio Herman Benjamin que na seara jurídica, a visão puramente técnica de consumidor, arraigada ao conceito econômico não é inteiramente aceita pelo direito, visto que as considerações políticas têm o condão de ampliar ou restringir este conceito, que após ser remodelado pela doutrina e jurisprudência, poderia ter um efeito diverso do pretendido inicialmente pelo legislador. ${ }^{5}$

Logo, a problemática que consiste em determinar a noção hodierna de consumidor está vinculada aos avanços experimentados pela corrente de proteção dos consumidores, que nas últimas décadas, cada vez mais ampliou o leque de pessoas consideradas carecedoras de uma proteção especial no tocante às relações de consumo.

Por conseguinte, pondera Carlos Lasarte Álvarez que em termos gerais, podem-se distinguir duas noções diferentes de consumidor, sendo uma concreta, calcada fundamentalmente nas pessoas que adquirem bens ou serviços para uso privado e uma noção ampla ou abstrata, que inclui todos os cidadãos como pessoas que aspiram ter uma melhor qualidade de vida. ${ }^{6}$

E o aludido jurista ainda complementa:

En realidad las nociones abstractas y concretas no son, pues, categorías homogéneas, puesto que las primeras constituyenel instrumento de que sirveel legislador para hacerse uma idea de la realidade que pretende regular y de los objetivos perseguidos mediante la acción legislativa; en tanto que las

\footnotetext{
${ }^{4}$ ALPA, Guido. Dirittoprivato dei consumi. - Bologna: II Mollno, 1986. p. 23.

5 BENJAMIN, Antônio Herman de Vasconcellos. O conceito jurídico de consumidor. In: RT 628. - São Paulo: Revista dos Tribunais, 1988. p.74.

${ }^{6}$ ÁLVAREZ, Carlos Lasarte. Manual sobre protección de consumidores y usuários. 5. ed. - Madrid: Dykinson, 2013. p. 53.
} 
segundas, como se comprobará, constituyenel instrumento técnico mediante el que se acotaelámbito de aplicación de las normas promulgadas o proyectadas. ${ }^{7}$

Depreende-se, portanto, que a noção concreta é a que permite o exercício pleno e individual dos direitos do consumidor, sendo essa baseada em um critério subjetivo, é utilizada tanto pelo legislador pátrio como o da União Europeia para o desenvolvimento dos textos legais.

O conceito legal de consumidor está expressamente enunciado no art. $2^{\circ}$ da Lei 8.078/1990, que dispõe que "Consumidor é toda pessoa física ou jurídica que adquire ou utiliza produto ou serviço como destinatário final". Portanto, observando-se o teor desse dispositivo, o consumidor pode ser tanto uma pessoa física como jurídica, sem qualquer distinção.

A respeito da pessoa jurídica consumidora no Brasil, outras são as perplexidades levantadas, porém foi acertada a escolha do legislador em incluir a pessoa jurídica como sujeito de direito na relação de consumo, conforme a lição de José Geraldo Brito Filomeno:

Prevaleceu, entretanto, como de resto em algumas legislações alienígenas inspiradas na nossa, a inclusão das pessoas jurídicas igualmente como consumidores de produtos e serviços, embora com a ressalva de que assim são entendidas aquelas como destinatárias finais dos produtos e serviços que adquirem, e não como insumos necessários ao desempenho de sua atividade lucrativa. ${ }^{8}$

Nessa senda, também defende a inclusão da pessoa jurídica como consumidora Júlio Moraes Oliveira, através da teoria do finalismo mitigado, que tem por escopo a relativização da vulnerabilidade no tratamento do consumidor-empresário, que de acordo com o referido jurista, o consumidor pode ser tanto um empresário individual quanto uma socie-

\footnotetext{
7 ÁLVAREZ, Carlos Lasarte. Manual sobre protección de consumidores y usuários. 5. ed. - Madrid: Dykinson, 2013. p. 53.

${ }^{8}$ FILOMENO, José Geraldo Brito. Código brasileiro de defesa do consumidor comentado pelos autores do anteprojeto. 8. ed. - Rio de Janeiro: Forense, 2004. p. 32.
} 
dade empresária, mas tal fato não generaliza a aplicação do Código de Defesa do Consumidor de maneira livre e irrestrita, devendo a análise ser feita sobre a figura do próprio consumidor, de acordo com o caso concreto. ${ }^{9}$

O referido jurista ainda destaca que além das espécies tradicionais de vulnerabilidade consolidadas pela doutrina e jurisprudência, outros elementos como a dependência do produto, o monopólio da produção, a natureza adesiva do contrato ou a extrema necessidade de obtenção de um bem ou serviço podem configurar tal definição.

Sendo assim, uma vez presentes os elementos da relação de consumo, é irrelevante a discussão sobre o enquadramento da pessoa ao conceito, visto que a vulnerabilidade do consumidor é elemento essencial da relação de consumo. $\mathrm{O}$ fato de a pessoa jurídica ser economicamente forte ou não, acaba sendo dispensável, pois tal comprovação confunde hipossuficiência com vulnerabilidade.

Nesse sentido, o Superior Tribunal de Justiça, já entendeu que existe a possibilidade de se mitigar a vulnerabilidade da pessoa jurídica, afastando a interpretação do Código de Defesa do Consumidor:

Processo Civil e consumidor. (...). Relação de consumo. Caracterização. Destinação final fática e econômica do produto ou serviço. Atividade empresarial. Mitigação da regra. Vulnerabilidade da pessoa jurídica. Presunção relativa. (...). Ao encampar a pessoa jurídica no conceito de consumidor, a intenção do legislador foi conferir proteção à empresa nas hipóteses em que, participando de uma relação jurídica na qualidade de consumidora, sua condição ordinária de fornecedora não lhe proporcione uma posição de igualdade frente à parte contrária. Em outras palavras, a pessoa jurídica deve contar com o mesmo grau de vulnerabilidade que qualquer pessoa comum se encontraria ao celebrar aquele negócio, de sorte a manter o desequilíbrio da relação de consumo. A paridade de armas entre a empresa-fornecedora e a empresa-consumidora afasta a presunção de

9 OLIVEIRA, Júlio Moraes. Consumidor-empresário. A defesa do finalismo mitigado.

- Belo Horizonte: Arraes, 2012. p. 103. 
fragilidade desta. Tal consideração se mostra de extrema relevância, pois uma mesma pessoa jurídica, enquanto consumidora, pode se mostrar vulnerável em determinadas relações de consumo e em outras não. (STJ - RMS 27.512/BA - Terceira Turma. Rel. Min. Fátima Nancy Andrighi - Dj. 20.08.2009).

Portanto, o principal indicativo previsto em lei para que uma pessoa seja considerada consumidora é o fato de ela ser a destinatária final do produto ou serviço, seja para uso pessoal ou familiar, e se vinculado a uma empresa, desde que esse produto ou serviço não constitua um elemento que fará parte do processo de produção.

\section{NOÇÃO E CONCEITO DE CONTRATO}

O entendimento da doutrina é pacífico ao salientar que o conceito de contrato é tão antigo quanto o momento em que o homem passou a se relacionar e a viver em sociedade, o que leva à conclusão de que o contrato é uma ideia trazida pela sociedade. Isto se torna evidente na definição romana, criada pelo jurista Ulpiano que, além de concisa é deveras correta: est pactio duorum pluriumve in idem placitum consensus, ou seja, o mútuo consenso de duas ou mais pessoas sobre o mesmo objeto. ${ }^{10}$

Washington de Barros Monteiro aduz que, muito embora várias codificações estrangeiras tenham se preocupado em definir o contrato, como o Código Civil Francês (art. 1.101) e o diploma Argentino (art. 1.137), o nosso Código Civil de 1916, bem como o de 2002 optou por não o fazer, seguindo a mesma linha dos códigos Alemão, Polonês, Suíço e o da antiga União das Repúblicas Socialistas Soviéticas, o que foi uma escolha acertada, pois não é tarefa do legislador ministrar definições, sendo esta função competente aos doutrinadores. ${ }^{11}$

Uma interessante comparação é feita por Flávio Tartuce, na qual o contrato é conceituado classicamente como sendo um negócio

\footnotetext{
${ }^{10}$ ULPIANO. Digesto, líber secundus, $X I V$, De pactis. Disponível em: <www.openlibrary.org>. Acesso em: 14 set. 2011.

${ }^{11}$ MONTEIRO, Washington de Barros. Op. cit., p. 18.
} 
jurídico bilateral ou plurilateral que visa à criação, modificação ou extinção de direitos e deveres com conteúdo patrimonial. ${ }^{12}$

A partir desse conceito, é possível observar a sua proximidade com a definição constante no art. 1.321 do Código Civil Italiano, cujo dispositivo estipula que: il contrato è l'accordo di due ou più parti per constituire, regolare ou estingueretra loro um rapporto giurídico patrimoniale (o contrato é um acordo de duas partes ou mais, para constituir, regular, ou extinguir entre elas uma relação jurídica patrimonial).

Semelhante a conceito, é o de Washington de Barros Monteiro, no qual o contrato é o acordo de vontades que têm por fim criar, modificar ou extinguir um direito. ${ }^{13}$

Para o professor LuisDiez-Picaso, a concepção moderna de cotrato não se limita meramente a um acordo de vontades entre os interessados, sendo que uma vez estabelecido, o contrato será a instituição central, a pedra angular, não apenas do Direito Civil, mas de todo o ordenamento jurídico. ${ }^{14}$

Dentro desse contexto, pode-se afirmar que o contrato é um ato jurídico em que se encontra presente a manifestação de vontades, com o escopo de adquirir, alterar ou extinguir relações jurídicas de caráter patrimonial, constituindo, por excelência, um negócio jurídico.

Para a sua existência válida e regular, é mister que sejam observadas as condições de validade do negócio jurídico, elencadas no artigo 104 do Código Civil. Portanto, também não se deve contrariar a lei, a boa-fé, os bons costumes, assim como sua função social e econômica.

Com efeito, o fundamento ético do contrato, na lição de Caio Mário da Silva Pereira, é a vontade humana, desde que esta seja em conformidade com a ordem jurídica, pois seu habitat é a ordem legal e seus efeitos são a criação de direitos e obrigações. ${ }^{15}$

Nesse sentido, é oportuno o ensinamento de Maria Helena Diniz, relacionado ao que foi exposto acima, ao salientar que o contrato repousa na ideia de um pressuposto factual elegido pelos contraentes e

\footnotetext{
12 TARTUCE, Flávio. Op. cit., p. 32.

${ }^{13}$ MONTEIRO, Washington de Barros. Op. cit., p. 19.

14 DÍEZ-PICAZO, LUIS. Fundamentos delderecho civil patrimonial. Introducción teoria del contrato. 6. ed. v. 1. - Pamplona: Civitas, 2007. p. 137.

15 SILVA PEREIRA, Caio Mário. Instituições de direito civil. 11. ed. Rio de Janeiro: Forense, 2003. v. 3. p. 7.
} 
reconhecido pela norma jurídica, tendo como base o efeito jurídico perseguido, norteado pela vontade humana, que atua conforme a ordem jurídica. $^{16}$

Depreende-se, portanto, que sempre do resultado de um mútuo consenso, oriundo de um negócio jurídico, estará constituído um contrato. Essa ilação nos evidencia que o contrato não se restringe apenas ao Direito das Obrigações, podendo estender-se a outros ramos do Direito Privado, como o casamento, por exemplo. Sua extensão pode também abarcar tratativas de Direito Público, pois são numerosos os contratos celebrados pela Administração Pública, o que faz do contrato o corolário das obrigações.

\section{A MASSIFICAÇÃO DOS CONTRATOS NO DIREITO CONSUMERISTA}

O Direito Contratual é dinâmico e está em constante processo de evolução, pois as formas contratuais mais utilizadas vão se tornando gradativamente mais refinadas, resultado das várias reestruturações sociais e econômicas, que for fim acabam dando gênese até mesmo a novas formas contratuais, como os contratos de franchising, leasing e engineering por exemplo.

Outro fenômeno que vem ocorrendo e que não poderia ser deixado de lado é o apresentado por Sílvio de Salvo Venosa, ao aduzir que com frequência, tem se visto o surgimento de coligações contratuais, que formam uma complexa rede negocial, em grupos interligados de contratos, revelando-se um novo desafio para o intérprete. Como exemplo, há de se supor serem necessários quantos contratos para se lançar no mercado um novo produto ou serviço de elevado nível de consumo, como um refrigerante ou um automóvel, sendo que em razão dessas mudanças econômico-sociais os princípios basilares, tais como o princípio da função social dos contratos, da boa-fé objetiva e da dignidade da pessoa humana nem sempre acabam sendo facilmente identificáveis aos olhos do operador do direito. ${ }^{17}$

16 DINIZ, Maria Helena. Curso de direito civil brasileiro: teoria das obrigações contratuais e extracontratuais. 27. ed. São Paulo: Saraiva, 2011. v. 3. p. 32.

17 VENOSA, Sílvio de Salvo. Direito Civil: contratos em espécie. 10. ed. São Paulo: Atlas, 2010. p. 4. 
Dentro desse contexto, o aludido jurista arremata:

A legislação protetiva do consumidor, com definição e compreensão no art. $2^{\circ}$ do Código de Defesa do Consumidor (Lei $\mathrm{n}^{\circ}$ 8.078/90), traz princípios ainda em ebulição e não totalmente assimilados pela doutrina e jurisprudência, fazendo-se presente permanentemente na atual relação contratual. Trata-se de conseqüência direta da complexidade crescente da sociedade, para a qual nem sempre os instrumentos clássicos são satisfatórios. O direito dos contratos também se apóia em tratados e convenções internacionais, a interferirem com frequiência na contratação interna. $^{18}$

Com efeito, a partir da segunda metade do século XX, os avanços tecnológicos e as novas relações mercantis enfraqueceram o princípio da igualdade formal entre as partes contratantes, relativizando o clássico o pacta sunt servanda, figurando injustiças em muitos casos.

Por conseguinte, Paulo Nalin assinala que o contratante do inicio deste século deparou-se com uma situação inusitada, criada pelas novas estruturas contratuais que, devido a uma preponderante função massiva, voltada ao escoamento e produção em escala industrial, acabou por despersonalizar a relação contratual. ${ }^{19}$

Atualmente, a massificação das relações contratuais intensificou a desproporção econômica do contrato, apagando a característica paritária nele presente e criando negócios jurídicos padronizados, submetendo a parte mais fraca apenas a aceitação, devido à impossibilidade de discussão de suas cláusulas.

As figuras contratuais mais convencionadas hoje, como o fornecimento de água e luz, de telefonia fixa ou móvel, de cartões de crédito, de empréstimo, de transporte, de seguro, de franquia, de locação residencial ou predial urbana, de leasing, de TV por assinatura, de plano de saúde, bem como outras dezenas de pactos usuais, são formulados através de contratos de adesão, cuja principal característica consiste na apresentação

\footnotetext{
18 VENOSA, Sílvio de Salvo. Op. cit., p. 4.

19 NALIM, Paulo Roberto. Do contrato: conceito pós moderno - em busca de sua formulação na perspectiva civil-constitucional. Curitiba: Juruá, 2001. p. 109.
} 
do conteúdo do contrato imposto por uma das partes, restando à outra, apenas a sua anuência.

O Código de Defesa do Consumidor preceitua no art. 54 que o contrato de adesão é aquele cujas cláusulas tenham sido aprovadas por autoridade competente ou estabelecidas unilateralmente pelo fornecedor de produtos e serviços, não sendo possível ao consumidor a modificação substancial de seu conteúdo.

Pablo Stolze Gagliano assevera que essa faculdade de aderência, último respaldo da bilateralidade negocial, coloca o aderente em situação desfavorável, visto que, na maioria das vezes, a parte que elabora o contrato detém um poder econômico superior ou o monopólio de um serviço tido como essencial. ${ }^{20}$

Nesse sentido, o pensamento de Georges Ripert, na análise do contrato de adesão é categórico:

Que há de contratual neste ato jurídico? É na realidade a expressão duma autoridade privada. O único ato de vontade do aderente consiste em colocar-se em situação tal que a lei da outra parte venha a se aplicar. $\mathrm{O}$ aderente entra nesse círculo estreito em que a vontade da outra parte é soberana. E, quando pratica aquele ato de vontade, o aderente é levado a isso pela imperiosa necessidade de contratar. É uma graça de mau gosto dizer-lhe: tu quiseste. A não ser que não viaje, que não use de transporte comum, que não trabalhe ao serviço de outrem, é-lhe impossível deixar de contratar. ${ }^{21}$

Entretanto, faz-se mister o reconhecimento de que o contrato de adesão, uma vez elaborado em conformidade com o princípio da função social e respeitando o princípio da dignidade da pessoa humana, torna-se um eficaz instrumento de contratação, considerando-se o incontável número de pessoas que o celebram diariamente, seja com diversas empresas, ou mesmo o Poder Público.

\footnotetext{
${ }^{20}$ GAGLIANO, Pablo Stolze; PAMPLONA FILHO, Rodolfo. Novo curso de direito civil. 7. ed. São Paulo: Saraiva, 2011. v. 4. tomo I. p. 42.

${ }^{21}$ RIPERT, Georges. A regra moral nas obrigações civis. 2. ed. Campinas: Bookseller, 2002. p. 112-113.
} 
E para realçar o exposto, o referido jurista salienta que não se trata peremptoriamente de uma desvantagem lançada em bloco em relação a todos os contratos de adesão e que a rigidez e permanência existentes nestes contratos se revelam como sólidas garantias de sua utilidade, sendo indispensável à vida econômica de um país e que apenas os abusos deste poder de contratar devem ser impedidos. ${ }^{22}$

Por fim, pode-se observar que o que torna nociva essa figura contratual é a abusividade no ato de elaboração do contrato, visto que a demanda de atendimento massivo exige respostas rápidas e padronizadas, mitigando faticamente a igualdade material entre as partes, porém buscando de forma adequada e segura o cumprimento do contrato celebrado em massa, sem desprezar o ser humano como indivíduo consciente e livre.

\section{A EFICÁCIA DA APLICAÇÃO DO PRINCÍPIO DA EQUI- VALÊNCIA MATERIAL NAS RELAÇÕES DE CONSUMO}

Este princípio pode ser considerado como um subproduto dos demais princípios até então apresentados, pois nele se encontram conjugados os princípios da solidariedade, previsto no artigo $3^{\circ}$, inciso I da Constituição Federal, o da função social dos contratos, disposto no artigo 421 do Código Civil e a cláusula geral da boa-fé objetiva, prevista no artigo 422 do mesmo diploma, em sintonia com o princípio da dignidade da pessoa humana.

Sobre a finalidade do referido princípio, a lição de Paulo Luiz Netto Lobô é de grande valor:

O princípio da equivalência material busca realizar e preservar o equilíbrio real dos direitos e deveres no contrato, antes, durante e após sua execução, para harmonização dos interesses. Esse princípio preserva a equação e o justo equilíbrio contratual, seja para manter a proporcionalidade inicial dos direitos e obrigações, seja para corrigir os desequilíbrios supervenientes, pouco importando que as mudanças de circunstâncias pudessem ser previsíveis. O que inte-

${ }^{22}$ RIPERT, Georges. Op. cit., p. 116. 
ressa não é mais a exigência cega de cumprimento do contrato, forma como foi assinado ou celebrado, mas se sua execução não acarreta vantagem excessiva para uma das partes e desvantagem excessiva para a outra, aferível objetivamente, segundo as regras da experiência ordinária. O princípio clássico pacta sunt servanda passou a ser entendido no sentido de que o contrato obriga as partes contratantes nos limites do equilíbrio dos direitos e deveres entre elas. ${ }^{23}$

Em linhas gerais, em se tratando de uma situação em que as circunstâncias se tornem excessivamente adversas e de forma imprevisível, levando ao comprometimento da relação contratual na forma esperada e ao tempo vigente de sua estipulação, o conteúdo do contrato de trato sucessivo ou diferido poderá ser revisto, conforme dispõe o art. 478 do Código Civil e os enunciados 17624 e 36725 , aprovados na III Jornada de Direito Civil, promovida pelo Conselho de Justiça Federal.

A jurisprudência é elucidativa nesse sentido:

COMPRA E VENDA. Laranja. Preço. Modificação substancial do mercado. O contrato de compra e venda celebrado para o fornecimento futuro de frutas cítricas (laranja) não pode lançar as despesas à conta de uma das partes, o produtor, deixando a critério da compradora a fixação do preço. Modificação substancial do mercado que deveria ser suportada pelas duas partes, de acordo com a boa-fé objetiva (art. 131 do C. Comercial). Recurso conhecido e provido. (STJ, REsp 256.456/SP; REsp (2000/0039981-7), DJ, 7-5-2001, p. 147; JBCC, v. 191, p. 234, RDR, v.

${ }^{23}$ LOBÔ, Paulo Luiz Netto. Princípios sociais dos contratos no CDC e no novo código civil. Jus Navigandi, Teresina. ano 7. n. 55. 2002. Disponível em: <http://jus.com.br/revista/texto/2796>. Acesso em: 25 fev. 2012.

${ }^{24}$ Enunciado 176: Em atenção ao princípio da conservação dos negócios jurídicos, o art. 478 do Código Civil de 2002 deverá conduzir, sempre que possível, à revisão judicial dos contratos e não à resolução contratual.

${ }^{25}$ Enunciado 367: Em observância ao princípio da conservação do contrato, nas ações que tenham por objeto a resolução do pacto por excessiva onerosidade, pode o juiz modificálo equitativamente, desde que ouvida a parte autora, respeitada a vontade e observando o contraditório. 
20, p. 400, rel. Min. Ruy Rosado de Aguiar, j. 22-32001, $4^{\mathrm{a}}$ Turma).

Nessa conjuntura, pode-se observar que o artigo 317 do Código Civil é esclarecedor ao tratar de maneira expressa a teoria da imprevisão, que no entendimento de Flávio Tartuce, a denominação mais adequada seria revisão obrigacional ou contratual por imprevisibilidade. ${ }^{26}$

É também o que se pode inferir de acordo com o enunciado n. 17 da I jornada de Direito Civil, promovida em setembro de 2002, que dispõe sobre a interpretação da expressão "motivos imprevisíveis" constante do art. 317 do novo Código Civil, que deve abarcar tanto causas de desproporção não previsíveis como também causas previsíveis, mas de resultados imprevisíveis.

Com efeito, acatado estará o princípio da equivalência material, considerando-se a teoria da imprevisão, disposta no artigo 317 do Código Civil, combinado com os artigos 478 a 480 do referido diploma.

Para que se tenha a revisão judicial do contrato, faz-se mister o atendimento dos requisitos básicos, tais como:

a) os motivos supervenientes à conclusão da obrigação devem ser imprevisíveis;

b) devem recair sobre as obrigações de trato sucessivo ou diferidas, estando excluídas as obrigações instantâneas ou momentâneas;

c) a desproporção entre as prestações devidas deve ser manifesta, levando em conta as prestações sob a ótica do critério objetivo;

d) os motivos geradores do desequilíbrio não podem ser imputados ao lesado;

e) o reequilíbrio da prestação deve ser postulado pela parte, vedado ao juiz implementá-lo de ofício.

Nesse sentido, já decidiu o Superior Tribunal de Justiça:

(...) Os requisitos para caracterização da onerosidade excessiva são: o contrato de execução continuada ou diferida, vantagem extrema de outra parte e acontecimento extraordinário e imprevisível,

\footnotetext{
26 TARTUCE, Flávio. Direito civil: direito das obrigações e responsabilidade civil. São Paulo: Método, 2010. 5. ed. v. 2. p. 124.
} 
cabendo ao juiz, nas instâncias ordinárias, e diante do caso concreto, a averiguação da existência de prejuízo que exceda a álea normal do contrato, com consequente resolução do contrato diante do reconhecimento de cláusulas abusivas e excessivamente onerosas para a prestação do devedor. (STJ, Quarta Turma. REsp. 1.034.702-ES. Rel. Min. João Otávio de Noronha. Dj. 15.04.2008). dáticos.

Cumpre agora, detalhar cada requisito para fins meramente di-

No primeiro requisito, é oportuno salientar que esse não trata apenas da álea normal, na qual se consideram os acontecimentos previsíveis com resultados previsíveis, pois todo contrato, cujo adimplemento se dá na forma de trato sucessivo ou diferido, estará sujeito a algum tipo de risco.

Sendo assim, as partes devem sempre encontrar respaldo no cuidado objetivo, comportando-se prudentemente e antevendo as situações mais óbvias, que podem ser legitimamente esperadas pelos contratantes, conforme a justa expectativa ao término da relação contratual.

Nessa senda, tem-se por superveniente o fato imprevisível anterior ou coetâneo à conclusão do contrato, cabendo à hipótese da figura jurídica da lesão, expressa no artigo 157 do Código Civil, resultando na anulabilidade ou na revisão de seus termos, de acordo com o parágrafo $2^{\circ}$ do aludido dispositivo, obedecendo a regra utile per inutile non vitiatur, que no vernáculo significa: $O$ útil não é viciado pelo inútil.

O segundo requisito versa sobre a questão temporal do adimplemento, excluindo as formas momentâneas ou instantâneas, visto que essas se perfazem em um curto lapso de tempo, não podendo dar ensejo a uma causa superveniente.

Somente o contrato cujo adimplemento ocorre na forma diferida ou de trato sucessivo, pode ser objeto da revisão obrigacional por imprevisibilidade, pois se trata de um acordo que se procrastina através do tempo, sendo suscetível de causas supervenientes.

Cumpre salientar que o artigo 317 está inserido na parte referente ao pagamento, ou seja, além das obrigações de dar pecúnias, estão incutidas as obrigações de fazer e não fazer. 
O terceiro requisito trata da desproporção manifesta, oriunda de razões supervenientes e imprevisíveis, que não podiam ser apreciadas pelas partes no inicio do contrato.

Maria Helena Diniz aduz que a apuração desse requisito deve ser feita de forma rigorosa, visto que a imprevisibilidade e a extraordinariedade ocorre quando as partes, no momento da celebração do contrato, não têm condições de antever a manifestação de um evento anormal. ${ }^{27}$

Logo, a análise desse requisito não é objetiva, mas sim subjetiva, visto tratar-se da universalidade do contexto econômico, que oferece a desproporcionalidade negocial, afetando determinadas regiões ou mesmo situações fáticas, atingindo a todos nela envolvidos.

Inclusive, a esse respeito, tal entendimento é afirmado no enunciado 366, aprovado pelo Conselho de Justiça Federal na IV Jornada de Direito Civil. $^{28}$

Se alguém contrata e ulteriormente a onerosidade decorrer do insucesso do negócio, levando o contratante a endividar-se, resultando no seu empobrecimento, não caberá a revisão contratual. Entretanto, se durante o transcurso do contrato, o rumo da economia verter para outra direção, causado por um desequilíbrio que venha a desfavorecer o contratante, gerando instabilidade negocial, será cabível a revisão contratual com o escopo de eliminar a onerosidade excessiva de uma ou ambas as partes.

O quarto requisito exclui a possibilidade de se imputar os acontecimentos imprevisíveis e supervenientes, geradores da desproporção das prestações, à parte lesada, conforme a antiga máxima: nemo auditur propriam turpitudinem allegans, ou seja, que ninguém pode se defender alegando a própria torpeza.

Portanto, é mister que a causa do evento seja estranha ao comportamento daquele que aufere os benefícios da reestruturação do liame jurídico contratual, devendo esse acontecimento ser sempre inusitado à parte lesada, não tendo essa, concorrido de qualquer forma para sua ocorrência.

\footnotetext{
27 DINIZ, Maria Helena. Código civil anotado. 15. ed. - São Paulo: Saraiva, 2010. p. 399.

${ }^{28}$ Enunciado 366: O fato extraordinário e imprevisível causador de onerosidade excessiva é aquele que não está coberto objetivamente pelos riscos próprios da contratação.
} 
O último requisito dispõe que o reequilíbrio da prestação somente deve ocorrer a pedido da parte, sendo impossível ao juiz fazê-lo de ofício, ficando adstrito ao requerimento da parte lesada.

O Superior Tribunal de Justiça já decidiu que o aumento de custos sobre qualquer estipulação contratual não pode ser imposto unilateralmente, devendo tais revisões com o propósito de se reajustar o valor da prestação no contrato serem judiciais, conforme a ementa a seguir:

CLAUSULA "REBUS SIC STANTIBUS". Ação de cumprimento de obrigações contratuais de venda de título de clube de lazer, com direito ao uso de 'flat'. Pretensão do clube ao prévio recebimento de preço adicional. Ajustado o negócio pelo preço certo de 1.600 ORTN'S, em contrato datado de 28 de fevereiro de 1986, e paga a totalidade do preço, não poderá a outorgante negar-se a admitir a outorgada como sócia e a entregar-lhe as chaves do 'flat'. Não cabe a outorgante impor unilateralmente, sem ação própria, a outra parte o reajuste decorrente de invocado exorbitante aumento dos custos de construção. Recurso especial não conhecido. (STJ, REsp7884/SP; REsp 1991/0001759-0; DJ 09/12/1991 p. 18036; JBCC vol. 164 p. 252; Rel. Min. Athos Carneiro, j. 22/10/1991, $4^{\mathrm{a}}$ Turma).

Todavia, não há óbice que impeça as partes de acordarem a revisão consensual, ou mesmo a convenção de arbitragem, nos moldes da Lei $\mathrm{n}^{\circ}$ 9.307, de 23 de setembro de 1991, incidindo assim, o princípio da autonomia privada.

$\mathrm{Na}$ seara consumerista, o Código de Defesa do Consumidor prevê a revisão contratual no seu art. $6^{\circ}$, inciso $\mathrm{V}$, para fatos supervenientes, ou seja, a alteração das circunstâncias iniciais do negócio celebrado, o que não se confunde com a teoria da imprevisão ou vícios de formação do negócio.

A jurisprudência colaciona o que foi exposto:

(...) É direito do consumidor a revisão das cláusulas contratuais tornadas excessivamente onerosas por fato superveniente, assim podendo compreender a 
súbita e inesperada alteração da política monetária e cambial, com elevação do dólar norte-americano, e os reflexos causados no contrato de leasing ajustados com cláusula de variação cambial. Recurso provido. (TJRJ, $18^{\mathrm{a}}$ Câmara de Direito Privado. Rel. Min. Jorge LuisHabib. Dj. 29.02.2000).

O principal fator que torna a revisão contratual do Código de Defesa do Consumidor mais avançada, é a não exigência de fato imprevisível, bastando apenas que haja o desequilíbrio contratual ou a onerosidade excessiva.

Nessa senda, é de grande valor a lição de Claudia Lima Marques:

A norma do art. $6^{\circ}$ do $\mathrm{CDC}$ avança, em relação ao Código Civil (arts. 478-480 - Da resolução por onerosidade excessiva), ao não exigir que o fato superveniente seja imprevisível ou irresistível apenas exibe a quebra da base objetiva do negócio, a quebra de seu equilíbrio intrínseco, a destruição essencial do contrato. Em outras palavras, o elemento autorizador da ação modificadora do Judiciário é o resultado objetivo da engenharia contratual, que agora apresenta mencionada onerosidade excessiva para o consumidor, resultado de simples fato superveniente, fato que não necessita ser extraordinário, irresistível, fato que podia ser previsto e não foi. ${ }^{29}$

Com efeito, é deveras acertada tal inovação, visto que está perfeitamente favorável ao princípio da vulnerabilidade, disposto no art. $4^{\circ}$ do Código de Defesa do Consumidor, prescindido, portanto, da prova dos elementos subjetivos, vez que já estão presumidos pelo microssistema.

Para concluir esse tópico, vale frisar a lição de Paulo Luiz Netto Lobô:

\footnotetext{
${ }^{29}$ MARQUES, Claudia Lima; BENJAMIN, Antônio Herman V; BESSA, Leonardo Roscoe. Manual de direito do consumidor. 3. ed. São Paulo: Editora Revista dos Tribunais, 2010. p. 71.
} 
O princípio da equivalência material rompe a barreira de contenção da igualdade jurídica e formal, que caracterizou a concepção liberal do contrato. Ao juiz estava vedada a consideração da desigualdade real dos poderes contratuais ou o desequilíbrio de direitos e deveres, pois o contrato fazia lei entre as partes, formalmente iguais, pouco importando o abuso ou exploração da mais fraca pela mais forte. O princípio da equivalência material desenvolve-se em dois aspectos distintos: subjetivo e objetivo. $\mathrm{O}$ aspecto subjetivo leva em conta a identificação do poder contratual dominante das partes e a presunção legal de vulnerabilidade. (...) Essa presunção é absoluta, pois não pode ser afastada pela apreciação do caso concreto. $\mathrm{O}$ aspecto objetivo considera o real desequilíbrio de direitos e deveres contratuais que pode estar presente na celebração do contrato ou na eventual mudança do equilíbrio em virtude de circunstâncias supervenientes que levem a onerosidade excessiva para uma das partes. ${ }^{30}$

A base do contrato deve ser mantida do seu início à sua conclusão, vale dizer que as circunstâncias do momento em que a relação contratual se originou não podem sofrer mudanças a ponto de comprometer toda a estrutura do negócio jurídico, colocando os contratantes em situação de injustificada desproporção, atentando contra a comutatividade que deve ser preservada no contrato.

Em outras palavras, o contrato não pode gerar uma situação exploratória de uma parte sobre a outra, especialmente a parte tida como vulnerável, pois estará assim descumprindo o papel sociológico da função social, necessitando ser revisado pelo órgão judicante.

\section{CONCLUSÃO}

As ciências jurídicas são como organismos vivos, impulsionados pelas necessidades e demandas do homem, acompanhando-o através da história, justificando-se assim a máxima ubi societas, ibi jus.

${ }^{30}$ LOBÔ, Paulo Luiz Netto. Op. cit. 
Com o advento do Código Civil de 2002, houve forte aproximação principiológica entre esse Código e o Código de Defesa do Consumidor no que tange à regulação contratual, uma vez que ambos incorporam a nova teoria geral dos contratos.

Observa-se, portanto, que Código de Proteção e Defesa do Consumidor é fruto de profundas transformações sociais e políticas ocorridas no século XX, evidenciando-se o anseio social por uma melhor concepção de justiça.

A relação entre consumidor e fornecedor, a proteção contratual e a vulnerabilidade são temas em constante processo de maturação, visto que a busca por um tratamento justo e equânime requer tempo e estudo.

O Direito do Consumidor representa uma forma de humanização do Direito, diferentemente do que se encontrava no Código Civil de 1916, marcado pelo rigor do pacta sunt servanda. Em síntese, as novas vertentes desenvolvidas no Código de Defesa do Consumidor, interligadas ao Código Civil de 2002 e a Constituição Federal, consubstanciam os princípios da dignidade da pessoa humana, da igualdade e da solidariedade.

\section{REFERÊNCIAS BIBLIOGRÁFICAS}

ALPA, Guido. Dirittoprivato dei consumi. - Bologna: II Mollno, 1986. ÁLVAREZ, Carlos Lasarte. Manual sobre protección de consumidores y usuários. 5. ed. - Madrid: Dykinson, 2013.

BENJAMIN, Antônio Herman de Vasconcellos. O conceito jurídico de consumidor. In: RT 628. - São Paulo: Revista dos Tribunais, 1988.

COSTA MACHADO, Antônio Cláudio da. (Org.); CUNHA FERRAZ, Anna Cândida da. (Coord.). Constituição Federal interpretada. 3. ed. Barueri: Manole, 2012.

DÍEZ-PICAZO, LUIS. Fundamentos delderecho civil patrimonial. Introducción teoria del contrato. 6. ed. v. 1. - Pamplona: Civitas, 2007.

DINIZ, Maria Helena. Código civil anotado. 15. ed. - São Paulo: Saraiva, 2010.

Curso de direito civil brasileiro: teoria das obrigações contratuais e extracontratuais. v. 3. 27. ed. São Paulo: Saraiva, 2011. 
FILOMENO, José Geraldo Brito. Código brasileiro de defesa do consumidor comentado pelos autores do anteprojeto. 8. ed. Rio de Janeiro: Forense, 2004.

GAGLIANO, Pablo Stolze; PAMPLONA FILHO, Rodolfo. Novo curso de direito civil.v. 4. 7. ed. São Paulo: Saraiva, 2011.

LOBÔ, Paulo Luiz Netto. Princípios sociais dos contratos no CDC e no novo código civil. Jus Navigandi, Teresina. ano 7. n. 55. 2002. Disponível em: <http://jus.com.br/revista/texto/2796>.

MARQUES, Cláudia Lima. Manual de direito do consumidor. São Paulo: Revista dos Tribunais, 2008.

MARQUES, Cláudia Lima; BENJAMIN, Antônio Herman V; BESSA, Leonardo Roscoe. Manual de direito do consumidor. 3. ed. São Paulo: Editora Revista dos Tribunais, 2010.

MELLO. Sônia Maria Vieira de. O direito do consumidor na era da globalização: a descoberta da cidadania. - Rio de Janeiro: Renovar, 1998.

MONTEIRO, Washington de Barros. Curso de direito civil. v. 5. 37. ed. - São Paulo: Saraiva, 2010.

NALIM, Paulo Roberto. Do contrato: conceito pós moderno - em busca de sua formulação na perspectiva civil-constitucional. Curitiba: Juruá, 2001.

OLIVEIRA, Júlio Moraes. Consumidor-empresário. A defesa do finalismo mitigado. - Belo Horizonte: Arraes, 2012.

RIPERT, Georges. A regra moral nas obrigações civis.2. ed. Campinas: Bookseller, 2002.

SILVA PEREIRA, Caio Mário. Instituições de direito civil. 11. ed. Rio de Janeiro: Forense, 2003.

TARTUCE, Flávio. Direito civil: direito das obrigações e responsabilidade civil. São Paulo: Método, 2010. 5. ed. v. 2.

ULPIANO. Digesto, líber secundus, XIV, De pactis. Disponível em: <www.openlibrary.org>.

VENOSA, Sílvio de Salvo. Direito Civil: contratos em espécie. 10. ed. São Paulo: Atlas, 2010. 